\title{
EFFECT OF PHYSICAL RESTRAINT GUIDELINES ON NURSES' PERFORMANCE AT MANSOURA UNIVERSITY HOSPITALS ${ }^{1}$ Eman Mahmoud Hafez Mohamed, ${ }^{2}$ Amany Mohamed Shebl Abd Ellateef, ${ }^{3}$ Wafaa Ismail Sherief, ${ }^{4}$ Karima Fouad Elshamy, and ${ }^{5}$ Amira Ahmed Hasanin.
}

1, 2,3,4,5 Medical-Surgical Nursing Department, Faculty of Nursing-Mansoura University E-mail of corresponding author: eman_mina95@yahoo.com

\begin{abstract}
:
Physical restraint is a piece of equipment or device that restricts a patient's ability to move. Restraints may keep a patient from getting out of bed or moving arms and legs excessively. The aim of this study was to establish, apply basic guidelines for nurses that dealing with restrained patients and evaluate the effect of physical restraint guidelines on nurse's performance. Methods A Quasi experimental research design was used in this study. Sample all nurses (90) that dealing with physical restraint patients were selected from the Mansoura University Hospitals. Five tools were used for data collection. Results of the present study found that, the mean age of the nurses was $28.73 \pm 6.91$ years. In addition to all of the studied nurses had unsufficient practices score and $84.4 \%$ of them had unsufficient knowledge score as pretest, while $78.9 \%$ of the subject study had sufficient practice and $94.4 \%$ of them had sufficient knowledge after direct implementation physical restraint guidelines, on the other hand on the follow up phase the same study reveled that $63.3 \%$ of the nurses had sufficient practice while $76.7 \%$ had sufficient knowledge score regarding physical restraint application. The study concluded; there was significantly improvement in nurses' knowledge and practice concerning to physical restraint application after implementation of physical restraint guidelines.
\end{abstract}

Key words: Physical restraint, Guidelines, Nurses.

\section{Introduction:}

For many years, the use of physical restraints (PRs) has been a common and controversial practice occurring in medicine and nursing field. ${ }^{(1,2)}$

Physical restraints are methods that immobilize or reduce the ability of the patient to freely move his or her arms, legs, body or head. These are generally warranted to manage violent or selfdestructive behavior that achieves the immediate physical safety of the patient, staff or others. Physical restraint devices that may used for the patient safety include those that protect the patient from falling out of bed or permit the patient to participate in activities without the risk of physical harm. ${ }^{(3)}$

The presence of patient in intensive care environment can cause agitation and added stress by the presence of mechanical ventilator, multiple invasive procedures, fear, pain, anxiety, sensory overload, and disruption to sleep cycles, for these reasons physical restraint is used in acute care settings and intensive care environment to prevent the disruption of treatment process and removal of invasive tubes and devices. ${ }^{(4)}$

Complications or injuries linked to physical restraint, can be divided in to two types of injury, the first type was direct injury caused as a result of the external pressure from the restraining device and included lacerations, bruising or strangulation. The second type was indirect injury or adverse outcomes. This indirect injury related to the enforced immobility of a person, and included 
increased mortality rate, development of pressure sores, falls, or failure to be discharged home. ${ }^{(5)}$

In addition, patients in PRs have reported becoming physically uncomfortable with feelings of demoralization, isolation and loss of freedom. ${ }^{(5)}$

The responsible nurse, have a huge responsibility when caring for a restrained patient. Many times restraints are needed immediately and violent attacks on health care workers can happen. The emphasis on proper documentation of alternative methods is an absolute must. Obtaining a physician's order for physical restraints is a top priority as well. Rationale for the application of restraints must be discussed with the patient and family. Reassessment of proper restraint positioning and reevaluation of the patient's continued need. (6)

\section{Significant of the study}

Since nurses' perceptions and knowledge play an important role in physical restraint care practice, it was deemed important to develop a restraint policy and educate nurses to implement it because hospitals in Egypt have not any policies and there are illegal uses of restraint. $^{(7)}$

Recent studies carried out one hundred patients and thirty five nurses in Mansoura hospitals revealed most of restrained patient was developed many problems as; pressure sore, limb edema, restricted circulation, and skin laceration at restraint site. Regarding to nurses the same study found that, lack of nurses' knowledge and documentation of physical restraining, and recommended that there is a need for standard guidelines and policies for physical restraint practices in Egyptian hospitals. $^{(7)}$

\section{Aim of study:}

The aim of the present study was to establish basic guidelines for nurses that dealing with restrained patients, apply restraint guidelines on nurses that dealing with restrained patients and evaluate the effect of physical restraint guidelines on nurses' performance.

\section{Research question:}

Is there a difference in nurses' performances pre and post implementing restraint guidelines?

\section{Subjects \& Methods}

Study Design:

Quasi-experimental research designs were used in this study.

Setting:

This study was conducted at Emergency Hospital (ICU), Medical Specialized Hospital (medical words) and Neurology department at Mansoura University Hospital.

Subjects:

All available nurses that dealing with restrained patients ware accepted to participate in this study comprised of 90 nurses.

The nurses were selected based on the following criteria

Inclusion criteria:

- All nurses from both sexes.

- All nurses dealing with restrained patients.

- Nurses with all level of education.

Tools:

The following tools will be utilized to collect data pertinent to the study.

\section{Personal characteristics for nurses:}

To assess, age, sex, marital status, educational level, years of experience and place of working.

\section{Nurses restraint interview sheet:} This composed of:

A. Basic nurse's knowledge about physical restraint which include (Is there enough information regarding physical restraint, sources of these information and is there especial policies for physical restraint in her department).

B. Knowledge regarding application of 
physical restraint which include (designs making, indications, types and contraindication for restraint used)

\section{Nursing practice Checklist:}

Clinical performance checklist for the nurses for wrist and leg restraint, which include (check the patient's ID bracelet against the assignment sheet. Also call the person by name, introduce him self to the patient, and explain procedure to the patient before beginning).

\section{The clinical practice restraint guidelines:}

Physical restraint guidelines It includes, restraint policy and all knowledge about physical restraint as; definition, types, causes, complications, and proper technique for using physical restraint.

\section{Physical restraint barriers:}

Which include barriers related nurses, barriers related patients and barriers related environment.

Method:

Consisted of:

Preparatory phase:

1. It includes reviewing of literature and theoretical knowledge of the various aspects of this issue using books, articles, internet, and magazines in order to develop the data collection tools.

2. Test validity was used for the modified tools and the designed booklet to determine whether the tools cover the aim. The stage developed by a Jury of seven experts (assistant professors of medical-Surgical Nursing) from the Faculty of Nursing, Mansoura (4) and Zagazig University (3).

3. Test reliability of the proposed tools was done by cronbach's alpha test, showed a strong significant positive correlation between tests (A), retest (B) and retest $(\mathrm{C})$ in knowledge and practice items.

4. The pilot study was applied on 9 nurses $(10 \%)$ of the study sample with the selected criteria to test the applicability of tools, arrangement of items, and estimate the time needed for each sheet, and then excluded from the study sample after modification of the tools.

5. Once the necessary approvals granted to proceed with the proposed study, subject who met sampling criteria \& agreed to participate in the study, interviewed by the investigator to collect the necessary data and implement the physical restraint guidelines after explanation for the purpose of the study.

6. This study applied on all of the available nurses that dealing with restrained patients in the previous mentioned setting, all of them consists of (90) nurses.

\section{Data collection:}

I. Assessment phase:

1. The investigator started by introducing himself to the nurses and giving them a brief idea about the aim of the study.

2. Verbal consent approval was obtained from each participating nurse prior to his /her inclusion into the study. Clarification of the nature and purpose of the study was done on the interview with each nurse.

3. The investigator emphasized participation is absolutely voluntary and confidential. Anonymity, privacy, safety and confidentiality will be absolutely assured throughout the whole study and the right to withdraw from the study at any time.

4. Each nurse was interviewed individually before applying the physical restraint guideline in order to collect the baseline nurse's data towered physical restraint using the study tools.

II. Planning phase:

The general objective of physical restraint guidelines: 
At the end of these guidelines, the nurses are expected to be able to demonstrate right information and proper application about physical restraint use to overcome restraint complications, and improve patients' health status.

The specific objectives of physical restraint guidelines:

At the end of these guidelines the nurses will be able to:

1. Identify restraint types.

2. Acquire knowledge about indication and contraindications to physical restraint.

3. Identify physical restraint barriers and restraint policy.

4. Identify physical restraint complications.

5. Applying physical restraint properly to the patient.

\section{Content of guidelines:}

The content of the program included educational and training component.

1. Theoretical components:

- Definition of physical restraint.

- Decision making of physical restraint.

- Causes of risk to patients of physical restraint.

- Types and alternatives of physical restraint.

- Physical restraint standard (ethics and policy).

- Complication and contraindications to restraint.

\section{Practical or Training part:}

Include the proper way of physical restraint applications.

The developed physical restraint guidelines were conducted in 4 sessions over one week after the selection of teaching methods and appropriate audiovisual aids. Three sessions concerned with theoretical part of restraint guidelines and one of them concerned with practical part.

Theoretical sessions: were carried out in 3 sessions. They included the following:
- First session:

At the beginning of this session, the investigator introduced his self and explained the objectives of the program. It included (definition, decision making, causes, types and risky patient) to physical restraint.

- Second session :

It covered items related to alternatives, policy and ethical considerations of physical restraint.

\section{- Third session:}

It covered items related to, when physical restraint become medically prohibited, and types of complication that arise from the physical restraint used.

- Training session: was carried out in one session.

This session include individualized training prescription for each nurse about ideal application for the different types of physical restraint, according to the available resources.

\section{Implementation phase:}

1. The developed physical restraint guidelines were implemented for the nurses individually. It was conducted in 4 sessions; each session took about 30 to 45 minutes (according to the activities required in each session and attention span of the nurses).

2. During each knowledge session the investigator used simple, brief and clear words. In addition to using bower point to facilitate the explanation to the nurses. At the end of each session, a brief summary was given by the investigator.

3. Moreover, The instructional booklet was given to each nurse in the study subject to attract their attention, motivate them, support them in their work with those risky patients for restraint and help for reviewing at any time.

4. Data collection covered a period of 6 months, started from the first of 
November 2012 to the end of May, 2013.

IV. Evaluation of program:

1. Each nurse in study group was interviewed immediately after applying the physical restraint guidelines sessions to assess his or her knowledge and practice using the study tools II and III, (post immediate test).

2. After six months from applying the physical restraint sessions, the evaluation of the studied subject were done (follow up test) to determine the effect of program on nurse's knowledge and practice regarding physical restraint by using the study tools: II and III

3. Comparison between pre, post, and follow up test finding was made to evaluate the effect of physical restraint guidelines on the nurse's knowledge and practice towered physical restraint applications.

\section{Results:}

The data collected were analyzed statistically and the results are categorized into 4 main parts which are: personal characteristics part, assessment of nurses' knowledge regarding physical restraint before and after restraint session's part, relation part, assessment of nurses' practice regarding physical restraint before and after restraint session's part, and relation part

\begin{tabular}{|c|c|c|}
\hline Age groups (in years) & 28 & 31.1 \\
$17-$ & 53 & 58.9 \\
$25-$ & 4 & 4.4 \\
$35-$ & 5 & 5.6 \\
$45-60$ & 63 & 70.0 \\
\hline \multicolumn{2}{|c|}{ mean $\pm \mathrm{SD}=28.73 \pm 6.91$} \\
\hline Level of education & 27 & 30.0 \\
Diplome & 11 & 12.2 \\
\hline BSc & 53 & 58.9 \\
\hline Years of experience & 26 & 28.9 \\
\hline
\end{tabular}

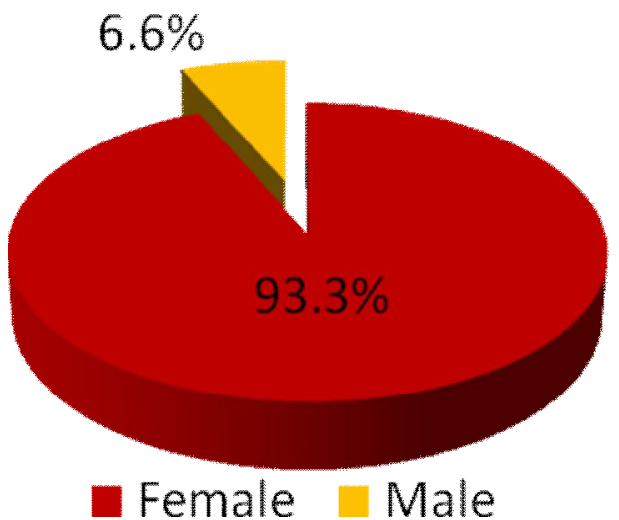

Fig. (5.1); Nurses Gender

Table (5.1): Personal Characteristics of Studied Nurses (no. $=90$ )

\begin{tabular}{c|c|c|} 
Personal & no. & $\%$ \\
Characteristics &
\end{tabular}




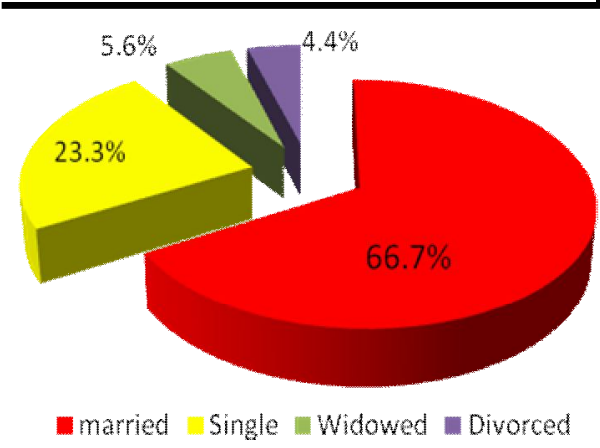

Fig. (5.2); Nurses Marital status

Table (5.1): Portrays that, about $58.9 \%$ of the studied nurses were in age group of $25-<35$ years with mean age \pm $\mathrm{SD}=28.73 \pm 6.91$. Regarding the level of education the studied nurses, it was found that, $70.0 \%$ of them had Diplome degree. Concerning the years of experience, it was found that $58.9 \%$ of the studied nurses had $5-<10$ years of experience with mean \pm $\mathrm{SD}=9.86 \pm 7.22$.

Figure (5.1): Shows that $93.3 \%$ of the studied nurses were females.

Figure (5.2): Reveals that $66.7 \%$ of the studied sample was married.

Table (5.2): Reveals that, $84.4 \%$ of the studied nurses in pre test had unsatisfactory knowledge regarding physical restraint, while in post implementing nursing guidelines, it found that $94.4 \%$ of them had satisfactory improvement in total knowledge score about physical restraint with highly statistical significant difference at pre vs. post test $\left(\mathrm{Z}=-8.310\right.$ at $\left.\mathrm{p} \leq 0.000^{* *}\right)$.

Concerning to follow up test, the same table found that $76.7 \%$ of the nurses had satisfactory knowledge regarding restraint, with highly statistical significant difference at pre vs. FU test and Post vs. FU test $(\mathrm{Z}=-6.822$ at $\mathrm{p}$ $\left.\leq 0.000^{* *}\right) \&\left(\mathrm{Z}=-3.411\right.$ at $\left.\mathrm{p} \leq 0.001^{* *}\right)$ respectively.
Table (5.2): Total Knowledge Score Pre, Post and Follow Up Test of Restraint Guidelines: $(\mathrm{n}=90)$ :

\begin{tabular}{|l|c|c|c|c|}
\hline \multirow{2}{*}{ Items } & \multicolumn{3}{|c|}{ Total nurse's knowledge score } \\
\cline { 2 - 5 } & \multicolumn{2}{|c|}{ Satisfactory } & \multicolumn{2}{c|}{ Un Satisfactory } \\
\cline { 2 - 5 } & no. & $\%$ & no. & $\%$ \\
\hline Pre test & 14 & 15.6 & 76 & 84.4 \\
\hline Post test & 85 & 94.4 & 5 & 5.6 \\
\hline FU test & 69 & 76.7 & 21 & 23.3 \\
\hline \multirow{2}{|cy}{$\mathbf{Z}$} & \multicolumn{2}{|c|}{ P-value } \\
\cline { 2 - 4 } $\begin{array}{l}\text { Pre vs. } \\
\text { Post test }\end{array}$ & \multicolumn{2}{|c|}{-8.310} & \multicolumn{2}{|c|}{$* * 0.000$} \\
\hline $\begin{array}{l}\text { Pre vs. } \\
\text { FU test }\end{array}$ & \multicolumn{2}{|c|}{-6.822} & \multicolumn{2}{|c|}{$* * 0.000$} \\
\hline $\begin{array}{l}\text { Post vs. } \\
\text { FU test }\end{array}$ & \multicolumn{2}{|c|}{-3.411} & $* * 0.001$ \\
\hline
\end{tabular}

$(* * *)$ Extremely significant difference, $\mathrm{P} \leq$ 0.0001

Table (5.3): Distribution of Nurses Dealing with Restraint Patient according to their Total Practice Score Pre, Post and FU Applications of Restraint Guidelines: $(\mathrm{n}=90)$

\begin{tabular}{|l|c|c|c|c|}
\hline \multirow{2}{*}{ Items } & \multicolumn{2}{|c|}{ Total nurse's Practice score } \\
\cline { 2 - 5 } & Satisfactory & \multicolumn{2}{c|}{ Un Satisfactory } \\
\cline { 2 - 5 } & no. & $\%$ & no. & $\%$ \\
\hline Pre test & 0 & 0.0 & 90 & 100.0 \\
\hline Post test & 71 & 78.9 & 19 & 21.1 \\
\hline FU test & 57 & 63.3 & 33 & 36.7 \\
\hline \multirow{2}{*}{$\begin{array}{l}\text { Pre Vs. } \\
\text { Post test }\end{array}$} & \multicolumn{2}{|c|}{$\mathbf{Z}$} & \multicolumn{2}{|c|}{ P-value } \\
\cline { 2 - 5 } $\begin{array}{l}\text { Pre Vs. } \\
\text { FU test }\end{array}$ & \multicolumn{2}{|c|}{-7.526} & \multicolumn{2}{|c|}{$* 0.000$} \\
\hline $\begin{array}{l}\text { FU Vs. } \\
\text { post test }\end{array}$ & \multicolumn{2}{|c|}{-2.401} & \multirow{2}{*}{$* 0.000$} \\
\hline
\end{tabular}

(*)Statistical significant difference, $\mathrm{P} \leq 0.05$ $(* * *)$ Extremely significant difference, $\mathrm{P}$ $\leq 0.0001$ 
Table (5.3); revealed that, $100.0 \%$ of the studied nurses in pre test had unsatisfactory practice regarding physical restraint applications, while in post implementing nursing guidelines, it was found that $78.9 \%$ of them had satisfactory improvement in total practice score about physical restraint applications, with highly statistical significant difference at pre vs. post test $(Z=-8.426$ at $\mathrm{p} \leq 0.001)$.
Concerning to follow up test, the same table found that $64.4 \%$ of the nurses had satisfactory practice regarding restraint applications, with highly statistical significant difference at pre vs. FU test $(Z=-7.550$ at $p \leq 0.001)$ and there was found a statistical significant difference at post vs. FU test $(Z=-2.401$ at $\mathrm{p} \leq 0.05)$

Table (5.4): Relations between Personal Characteristics and Nurse's Knowledge: $(n=90)$

\begin{tabular}{|c|c|c|c|c|c|c|c|c|c|c|c|c|}
\hline \multirow{3}{*}{$\begin{array}{c}\text { Personal } \\
\text { Characteristics }\end{array}$} & \multicolumn{4}{|c|}{ Pre test } & \multicolumn{4}{|c|}{ Post test } & \multicolumn{4}{|c|}{ FU test } \\
\hline & \multicolumn{2}{|c|}{ Satisfactory } & \multicolumn{2}{|c|}{$\begin{array}{c}\text { Un } \\
\text { satisfactory }\end{array}$} & \multicolumn{2}{|c|}{ Satisfactory } & \multicolumn{2}{|c|}{$\begin{array}{c}\text { Un } \\
\text { satisfactory }\end{array}$} & \multicolumn{2}{|c|}{ Satisfactory } & \multicolumn{2}{|c|}{$\begin{array}{c}\text { Un } \\
\text { satisfactory }\end{array}$} \\
\hline & no. & $\%$ & no. & $\%$ & no. & $\%$ & no. & $\%$ & no. & $\%$ & no. & $\%$ \\
\hline $\begin{array}{c}\text { Age groups } \\
\text { (in years): } \\
17- \\
25- \\
35- \\
45-60\end{array}$ & $\begin{array}{l}4 \\
6 \\
3 \\
1\end{array}$ & $\begin{array}{c}28.6 \\
42.9 \\
21.4 \\
7.1\end{array}$ & $\begin{array}{c}24 \\
47 \\
1 \\
4\end{array}$ & $\begin{array}{l}31.6 \\
61.6 \\
1.3 \\
5.3\end{array}$ & $\begin{array}{c}28 \\
53 \\
4 \\
0\end{array}$ & $\begin{array}{c}32.9 \\
62.4 \\
4.7 \\
0.0\end{array}$ & $\begin{array}{l}0 \\
0 \\
0 \\
5\end{array}$ & $\begin{array}{c}0.0 \\
0.0 \\
0.0 \\
100.0\end{array}$ & $\begin{array}{c}21 \\
41 \\
4 \\
3\end{array}$ & $\begin{array}{c}30.4 \\
59.4 \\
5.8 \\
4.3\end{array}$ & $\begin{array}{c}7 \\
12 \\
0 \\
2\end{array}$ & $\begin{array}{c}33.3 \\
57.1 \\
0.0 \\
9.5\end{array}$ \\
\hline $\mathbf{X}^{2}$ & \multicolumn{4}{|c|}{11.59} & \multicolumn{4}{|c|}{90.00} & \multicolumn{4}{|c|}{2.05} \\
\hline P-value & \multicolumn{4}{|c|}{$* 0.01$} & \multicolumn{4}{|c|}{$* * 0.000$} & \multicolumn{4}{|c|}{0.56} \\
\hline $\begin{array}{l}\text { Educational } \\
\text { level: } \\
\text { Diplome. } \\
\text { BSc. }\end{array}$ & $\begin{array}{c}10 \\
4\end{array}$ & $\begin{array}{l}71.4 \\
28.6\end{array}$ & $\begin{array}{l}53 \\
23\end{array}$ & $\begin{array}{l}69.7 \\
30.3\end{array}$ & $\begin{array}{l}59 \\
26\end{array}$ & $\begin{array}{l}69.4 \\
30.6\end{array}$ & $\begin{array}{l}4 \\
1\end{array}$ & $\begin{array}{l}80.0 \\
20.0\end{array}$ & $\begin{array}{l}50 \\
19\end{array}$ & $\begin{array}{l}72.5 \\
27.5\end{array}$ & $\begin{array}{c}13 \\
8\end{array}$ & $\begin{array}{l}61.9 \\
38.1\end{array}$ \\
\hline $\mathbf{X}^{2}$ & \multicolumn{4}{|c|}{0.016} & \multicolumn{4}{|c|}{0.25} & \multicolumn{4}{|c|}{0.86} \\
\hline P-value & \multicolumn{4}{|c|}{0.58} & \multicolumn{4}{|c|}{0.52} & \multicolumn{4}{|c|}{0.25} \\
\hline $\begin{array}{c}\text { Years of } \\
\text { experience: } \\
1- \\
5- \\
\geq 10\end{array}$ & $\begin{array}{l}3 \\
3 \\
8\end{array}$ & $\begin{array}{l}21.4 \\
21.4 \\
57.1\end{array}$ & $\begin{array}{c}8 \\
50 \\
18\end{array}$ & $\begin{array}{l}10.5 \\
65.8 \\
23.7\end{array}$ & $\begin{array}{l}11 \\
53 \\
21\end{array}$ & $\begin{array}{l}12.9 \\
62.4 \\
24.7\end{array}$ & $\begin{array}{l}0 \\
0 \\
5\end{array}$ & $\begin{array}{c}0.0 \\
0.0 \\
100.0\end{array}$ & $\begin{array}{c}9 \\
39 \\
21\end{array}$ & $\begin{array}{l}13.0 \\
56.5 \\
30.4\end{array}$ & $\begin{array}{c}2 \\
14 \\
5\end{array}$ & $\begin{array}{c}9.5 \\
66.7 \\
23.8\end{array}$ \\
\hline $\mathrm{X}^{2}$ & \multicolumn{4}{|c|}{9.68} & \multicolumn{4}{|c|}{13.03} & \multicolumn{4}{|c|}{0.689} \\
\hline P-value & \multicolumn{4}{|c|}{$* * 0.001$} & \multicolumn{4}{|c|}{$* * 0.001$} & \multicolumn{4}{|c|}{0.71} \\
\hline
\end{tabular}

(*) Statistical significant difference, $\mathrm{P} \leq 0.05$

(**) Highly statistically significant difference, $\mathrm{P} \leq 0.001$

Table (5.4); Reveals that, there was a statistically significant relation between nurses' age and their total knowledge scores in pre test phase as $(\mathrm{p} \leq 0.05)$ and a highly statistically significant relation was found in post implementing nurses' guidelines protocol at $(\mathrm{P}=\leq 0.001)$. While there was no statistically significant difference in follow up phase at $(\mathrm{P}>0.05)$.
Concerning the years of experience, the same table reveals a highly statistical significant relation at pre and post implementing nurses' guidelines regarding physical restraint as $(\mathrm{P}=\leq 0.001)$, while there was no statistically significant relation in follow up phase. In addition, there was no statistically significant relation between the educational level of the studied sample and their total knowledge at pre, post and follow up phases as $(>0.05)$. 
Table (5.5): Relations between Personal Characteristics and Nurse's Practice: $(n=90)$

\begin{tabular}{|c|c|c|c|c|c|c|c|c|}
\hline \multirow{3}{*}{$\begin{array}{c}\text { Personal } \\
\text { Characteristics }\end{array}$} & \multicolumn{4}{|c|}{ Post test } & \multicolumn{4}{|c|}{ FU test } \\
\hline & \multicolumn{2}{|c|}{ Satisfactory } & \multicolumn{2}{|c|}{ Un satisfactory } & \multicolumn{2}{|c|}{ Satisfactory } & \multicolumn{2}{|c|}{ Un satisfactory } \\
\hline & no. & $\%$ & no. & $\%$ & no. & $\%$ & no. & $\%$ \\
\hline Age groups (in years): & & & & & & & & \\
\hline $17-$ & 23 & 32.4 & 5 & 26.3 & 17 & 29.8 & 11 & 33.3 \\
\hline $25-$ & 45 & 63.4 & 8 & 42.1 & 36 & 63.2 & 17 & 51.5 \\
\hline $35-$ & 3 & 4.2 & 1 & 5.3 & 2 & 3.5 & 2 & 6.1 \\
\hline $45-60$ & 0 & 0.0 & 5 & 26.3 & 2 & 3.5 & 3 & 9.1 \\
\hline$X^{2}$ & \multicolumn{4}{|c|}{20.05} & \multicolumn{4}{|c|}{2.04} \\
\hline P-value & \multicolumn{4}{|c|}{$* * 0.000$} & \multicolumn{4}{|c|}{0.564} \\
\hline \multicolumn{9}{|l|}{ Educational level: } \\
\hline Diplome & 47 & 66.2 & 16 & 84.2 & 41 & 71.9 & 22 & 66.7 \\
\hline BSc. & 24 & 33.8 & 3 & 15.8 & 16 & 28.1 & 11 & 33.3 \\
\hline $\mathbf{X}^{2}$ & \multicolumn{4}{|c|}{2.316} & \multicolumn{4}{|c|}{0.276} \\
\hline P-value & \multicolumn{4}{|c|}{0.165} & \multicolumn{4}{|c|}{0.384} \\
\hline \multicolumn{9}{|l|}{ Years of experience: } \\
\hline $1-$ & 10 & 14.1 & 1 & 5.3 & 9 & 15.8 & 2 & 6.1 \\
\hline $5-$ & 45 & 63.4 & 8 & 42.1 & 31 & 54.4 & 22 & 66.7 \\
\hline$\geq 10$ & 16 & 22.5 & 10 & 52.6 & 17 & 29.8 & 9 & 27.3 \\
\hline$X^{2}$ & \multicolumn{4}{|c|}{6.80} & \multicolumn{4}{|c|}{2.201} \\
\hline P-value & \multicolumn{4}{|c|}{ *0.033 } & \multicolumn{4}{|c|}{0.333} \\
\hline
\end{tabular}

(*) Statistical significant difference, $\mathrm{P} \leq 0.05$

$(* * *)$ Extremely significant difference, $\mathrm{P} \leq 0.0001$ 
EFFECT OF PHYSICAL RESTRAINT GUIDELINES ON NURSES etc...

Table (5.6): Correlation co-efficient between total knowledge of Nurses and their practices Score Post and Follow up applications of guidelines $(n=90)$ :

\begin{tabular}{|c|c|c|c|c|c|c|}
\hline \multirow{3}{*}{$\begin{array}{c}\text { Total nurse's practice } \\
\text { score }\end{array}$} & \multicolumn{4}{|c|}{ Total nurse's knowledge score } & \multirow{3}{*}{$\mathbf{X}^{2}$} & \multirow{3}{*}{ P-value } \\
\hline & \multicolumn{2}{|c|}{ Satisfactory } & \multicolumn{2}{|c|}{ Un Satisfactory } & & \\
\hline & no. & $\%$ & no. & $\%$ & & \\
\hline $\begin{array}{l}\text { 1- Post test } \\
\text { Satisfactory } \\
\text { Un Satisfactory }\end{array}$ & $\begin{array}{l}71 \\
14\end{array}$ & $\begin{array}{l}83.5 \\
16.5\end{array}$ & $\begin{array}{l}0 \\
5\end{array}$ & $\begin{array}{c}0.0 \\
100.0\end{array}$ & 19.78 & $* * 0.000$ \\
\hline $\begin{array}{l}\text { 2- FU test } \\
\text { Satisfactory } \\
\text { Un Satisfactory }\end{array}$ & $\begin{array}{l}55 \\
14\end{array}$ & $\begin{array}{l}79.7 \\
20.3\end{array}$ & $\begin{array}{c}2 \\
19\end{array}$ & $\begin{array}{c}9.5 \\
90.5\end{array}$ & 34.15 & $* * 0.000$ \\
\hline
\end{tabular}

(***) Highly significant difference, $\mathrm{P} \leq 0.0001$

Table (5.5); Illustrated that, there was a highly statistically significant relation between the age, years of experience of the studied nurses' and their total practice scores at post implementing guidelines ( $p$ $\leq 0.001$ ), while there was no statistically significant relation at follow up phase $(\mathrm{p}>$ $0.05)$. As regard to the educational level of the studied sample there was no statistically significant difference at post and follow up phase $(\mathrm{p}>0.05)$.

Table (5.6): Reveals that total nurses' knowledge correlated positively with their total practices score in post and follow up phases of implementing physical restraint guidelines.

\section{Discussion:}

Physical restraints can be viewed differently by nurses. Physical restraints refer to"a manual method or mechanical device, material, or equipment attached or adjacent to the patient's body that he or she cannot easily remove and that restrict the patient's freedom. There are several types of physical restraint such as wrist, ankle, vest, belts, and handcuffs which can be used partially or totally to restrict the patient's movements ${ }^{(8,9)}$.

This study was carried out to answer the question and achieve these aims; establish basic guidelines for nurses that dealing with restrained patients, apply restraint guidelines on nurses that dealing with restrained patients and evaluate the effect of physical restraint guidelines on nurse's performance. The study results demonstrated significant improvements in nurses' knowledge and practice. The findings lead to accept the set question, with confirmation of the effectiveness of the guidelines.

Regarding to the nurse's characteristics, the present study revealed that more than half of the nurses were in age group (25-34) year. On the other hand most of them were female nurses and less than three quarter of the sample was married and had diplome degree. According to years of experience the same study found that more than half of the nurses had (5-10) years. Similarly Evans, et-al., (2002), found in their study that most of the nurses were in age group (2141) years, and the majority of them were female with years of experience between (6-10) years; while almost half of their nurses had school diplomas (tablel and fig. 1\&2). (11)

The significant improvements demonstrated at the post-guidelines phase when found that most of the nurses had sufficient knowledge regarding physical restraint which indicate that these nurses 
were in real need for such information. Moreover, the acquired knowledge was retained with no declines throughout the six-month follow-up, when found that more than three quarter of the nurses still have sufficient knowledge regarding physical restraint. The effect of the intervention was confirmed through multivariate analysis that identified the program attendance as a strong positive independent predictor of the knowledge score. The finding further indicates that the nurses continually use their knowledge and apply it to their daily practice, which helps recall and memorization (table 5.2).

It also shows that they were eager to learn and know about correct information regarding this practice of daily work. This eagerness to learn might be explained by the fact that many nurses believe that the restraining procedure is not ethically accepted; however, feel it is required in some situations for the benefit of the patient. They consider it as a "necessary evil". Therefore, if they are forced to do it, they need to know how to do it properly without harming the patient.

Our findings are in agreement with Kontio et al., (2012) who showed improvement in nurses' knowledge that was sustained after implementing their educational endeavor. ${ }^{(12)}$

The improvement in nurses' practices after the intervention was also noticeable since their practices before the guidelines were even worse compared with knowledge. In fact none of them had adequate practice at the pre-guidelines phase. While there was significant improvements demonstrated at the postguidelines phase when found that more than three quarter of the nurses had sufficient knowledge regarding physical restraint application. Like knowledge, the adequate practice continued throughout the follow-up, and the attendance of the program was the only independent predictor that positively influenced the practice score. (Table 5.3).

In agreement with our findings, Huang et al., (2009), who examined the effectiveness of a short-term 90-minut inservice education program in improving nurses' knowledge, attitudes, and selfreported practices related to physical restraint use. The results demonstrated significant improvements after program completion. ${ }^{(13)}$

On the same line with Taha and Ali (2013), reported that there was a positive significant improvement in nurses' practices after guidelines intervention this improvement continued and extend even after two months. The findings of the current study as well as this one highlight the need to provide short-term in-service education programs in acute care settings. $^{(14)}$

According to the present study findings, nurses' age and experience had an influence on their knowledge and practice improvements at ( $p$-value 0.000).

On the same line Cannon, et al., (2001) found that there was statistical significant difference between years of critical care experience of the nurses and nurse's knowledge regarding physical restraint use. This result may be due to the long period of spending time with irritable patients in the hospital which give the nurses chance to learn something regarding physical restraint. (Table, 5.4) $(15)$

In contrast with this Taha and Ali (2013), who revealed that nurses' age and experience had no influence on their knowledge and Practice scores' improvements. This indicates that the intervention program was beneficial to all nurses regardless their experience. This might be explained by the fact that the knowledge and practice scores were very low at the pre-guidelines phase, so that no relation could be detected. ${ }^{(14)}$ 
On the other hand there was no statistical significant deference between nurse's level of education with their knowledge and practice. This might be due to no body emphasized on physical restrain as an important subject on the school of nurses or even on the faculty of nursing which explain why there is no difference between levels of education for the nurses and nurse's knowledge regarding physical restrain. Similarly with Taha and Ali (2013), who revealed that nurses' qualification had no influence on their knowledge and practice scores' improvements (table, $5.4 \& 5.6$ ). ${ }^{(14)}$

These findings are consistent with those of Hantikainen and Kappeli, (2000) who found no differences in the perceptions of restraint use between qualified and unqualified nurses. However, in disagreement with this, Al-Khaled et al. (2011) revealed that nurses' higher qualification was associated with better performance in applying and maintaining physical restraints. $(16,17)$

There was an extremely statistical significant difference between total nurses' scores of knowledge and practice. This is certainly due to the effect of the educational guidelines which improved nurses' knowledge and practice. Nurses' knowledge and practice scores turned to be strongly and positively correlated. This is in fact an objective proof of the success of the guidelines intervention and the authenticity of our question (table, 5.6). These findings are consistent with those of Taha and Ali (2013) who found that there was a statistically significant strong positive correlation between nurses' scores of knowledge and practice. The reduction in the frequency of complications among restrained patients in their study may be attributed to the changes in nurses' practice which became adequate and based on satisfactory knowledge acquired during the program. ${ }^{(14)}$
Conclusion: The study concludes that relatively short-term in-service guidelines can significantly improve nurses' knowledge and practice concerning to physical restraint application. This success is attributed to that the guidelines are based on need assessment and integrate updated technology. After implementation of physical restraint guidelines, the present study showed that, the majority of them had satisfactory knowledge and more than three quarter of the nurses had satisfactory practice after direct implementation of restraint guidelines. While more than three quarter of the subject study had satisfactory knowledge and more than half of them had satisfactory practice score after six months from implementation of restraint guidelines.

\section{Recommendations:}

Based on the findings of this study, the following can be recommended:

- Organizations and health care providers adopt a standardized protocol to physical restraint, is recommended.

- The minimal level of restraint must be used to ensure patient safety and to facilitate treatment.

- Organizations should utilize a program of activities that supports a reduction in the use of physical restraint devices.

- Continuous training programs should be organized for the nurses to improve their knowledge regarding physical restraint application.

- Orientation programs should be utilized for newly jointed nurses to improve their practice and knowledge regarding restraint application.

- Continuous supervision from the head nurse to the staff nurses during physical restraint application and feed back should be done.

- Booklets about physical restraint should be available in each department using restraint in the hospitals. 


\section{Further study:}

- Effect of improving nurses' performance on physical restraint patients at ICU hospital.

- Physical Restraint Policy Standardized Care Process (SCP).

A randomized double blind

clinical trial is suggested to

further confirm the study

findings.

Conflict of interest:

- The authors declare that they have no conflict of interests.

\section{Acknowledgments:}

Thanks to all nurses and other health car staff on the wards involved.

Funding:

- No funding sources were provided.

\section{References:}

1. Edwards, N., Danseco, E., Heslin, K., Ploeg, 1., Santos, J., Stansfield, M., and Davies, B., (2006): Development and testing of tools to assess physical restraint use. Worldviews On EvidenceBased Nursing, 3(2): 73-85.

2. Minnick A, Mion L., Johnson M., Catrambone C., and Leipzig R., (2007): Prevalence and variation of physical restraint use in acute care settings in the US J, Nurs Scholarsh; 39 (1):30-37.

3. Timby B., (2013): Fundamental Nursing Skills and Concepts. $10^{\text {th }}$ edition. Wolters Kluwer Health. Lippincott, Williams, \& Wilkins P 409.

4. McCabe, D., Alvarez, C., McNulty, S., and Fitzpatrick, J.J. (2011): Perceptions of physical restraints use in the elderly among registered nurse and nurse assistants in a single acute care hospital. Geriatric Nursing, 32(1), 3945.

5. Huang, H., Chuang, Y., and Chiang, K.. (2009): Nurses' physical restraint knowledge, attitudes and practices: The effectiveness of an in-service education program. Journal of Nursing Research, 17(4), 241-248.

6. Mulryan and Kathleen (2005): "Designing a Restraint-Free Environment" In Clinical Nursing Skills \& Techniques, 4th ed, Louis: MosbyYear Book, PP: 74-78.

7. Hafez M., (2011): Problems Encountered Among Patients Utilizing Physical Restraint in Mansoura University Hospitals, Unpublished, Master thesis, Faculty of Nursing, Zagazig University.

8. Akansel N (2007): physical restraining practices among intensive care nurses in one University Medical Hospital in western Turkey. Health Science Journal 4 (1): 7-13.

9. Mion LC., (2008): Physical restraint in critical care settings: will they go away? Geriatr Nurs (29): 421-423.

10. Agens JE. (2010): Chemical and physical restraint use in the older person. BJMP 3(1):302.

11. Evans and Cotter V., (2008): Avoiding restraints in patients with dementia: understanding,prevention, and management are the keys. Am J Nurs; 108(3): 40-9.

12. Kontio R., ätönen H., Joffe G., Pitkänen A., and Lahti M., (2012): Impact of eLearning course on nurses' professional competence in seclusion and restraint practices: J Psychiatr Ment Health Nurs 20: 411-418.

13. Huang, H., Chuang, Y., and Chiang, K.. (2009): Nurses' physical restraint knowledge, attitudes and practices: The effectiveness of an inservice education program. Journal of Nursing Research, 17(4), 241-248.

14. Taha N., and Ali Z., (2013): Physical Restraints in Critical Care Units: Impact of a Training Program on Nurses' Knowledge and Practice and on Patients' Outcomes. J Nurs Care 2: 135. 
EFFECT OF PHYSICAL RESTRAINT GUIDELINES ON NURSES etc...

http://dx.doi.org/10.4172/2167-

1168.1000135

15. Cannon ME, Sprivulis P., and McCarthy J., (2008): Restraint practices in Australasian emergency departments. J N Z J Psychiatry, 35: 464-467

16. Hantikainen V., and Käppeli S., (2006): Using restraint with nursing home residents: a qualitative study of nursing staff perceptions and decision-making. J Adv Nurs; 32: 1196-1205.

17. Al-Khaled TH, Zahran EM, and El-Soussi AH (2011): Nurses' related factors influencing the use of physical restraint in critical care units. Journal of American Science 7(8):13-22. 